|| ISSN(online): 2589-8698 || ISSN(print): 2589-868X || International Journal of Medical and Biomedical Studies Available Online atwww.ijmbs.info

PubMed (National Library of Medicine ID: 101738825) Index Copernicus Value 2018: 75.71

ASSESSMENT OF THE SURGICAL PROFILE AMONG PATIENTS OF ILEAL PERFORATION

\title{
Dr. B.M.Soni
}

Associate Professor, Department of General Surgery, Pacific Medical College \& Hospital, Udaipur

Article Info: Received 02 May 2019; Accepted 26 June 2019

DOI: https://doi.org/10.32553/ijmbs.v3i7.469

Address for Correspondence: Dr. B.M.Soni

Conflict of interest: Nil

\begin{abstract}
Background: In various researches it was reported that perforations of gastrointestinal tract had been surgical emergencies. Some studies also reported that the proof of gastrointestinal tract perforations in ancient mummies. Gastrointestinal tract perforation occurs when a pathology of any specific disease involves the entire depth of the gastrointestinal tract

Material \& Methods: Patients who were diagnosed as perforation and peritonitis on the basis of laboratory diagnosis and clinical examination were enrolled by simple random sampling. Clearance from Institutional Ethics Committee was taken before start of study. Written informed consent was taken from each study participant.

Results: In the present study, out of total study participants abdominal pain was the most common presenting symptom present in patients which was followed by fever, abdominal distension and vomiting. On the basis of time of perforation, $4 \%$ cases presented within 12 hour, between 12 and 24 hour was reported among in $50 \%$ cases, in the rage of 24 and 48 hour seen in $24 \%$ patients, in the range of 48 and 72 hour reported in $12 \%$ cases, in range of 72 and 96 hour reported in $8 \%$ cases, and in range of 96 and 120 hour reported in $2 \%$ case. Near about all patients were operated in the range of 12 hours of hospitalization.

Conclusion: The most common presenting symptoms present among patients were abdominal pain, abdominal distension, vomiting, fever and obstipation. We found that majority of cases had circular perforation of typhoid at antimesenteric border which was followed by tubercular elliptical perforation on the antimesenteric border and traumatic type perforation.
\end{abstract}

Key words: Ileal perforation. primary closure, loop ileostomy

\section{INTRODUCTION}

In various researches it was reported that perforations of gastrointestinal tract had been surgical emergencies (1). Some studies also reported that the proof of gastrointestinal tract perforations in ancient mummies. Gastrointestinal tract perforation occurs when a pathology of any specific disease involves the entire depth of the gastrointestinal tract (2). Gastrointestinal tract perforation leads to the contamination of peritoneal cavity with intestinal contents. In various researches it was reported that perforations can be occurred anywhere in full length of gastrointestinal tract. In various researches it was reported that ileal perforation are common surgical emergencies especially in the tropical area of world and particularly in India (3). Some studies also reported that ileal perforations are accounts for near about $20 \%$ of total abdominal surgical emergencies. The most prevalent causes reported are tuberculosis and enteric fever (4).
In various researches it was reported that ileal perforation had an high incidence of mortality, longer hospital stays and economic burden on patients. previous studies were reported various causes of ileal perforation which includes tuberculosis, salmonella infection, Yersinia infection, cytomegalovirus, human immunodeficiency virus, histoplasma, A. lumbricoides, E. histolytica and Nonsteroidal antiinflammatory drugs (5). There were various operative procedures were reported in various researches which are simple primary repair, management by repair with ileo-transverse colostomy, management by single layer repair with an omental patch and management by resection and anastomosis and management by primary ileostomy (6). We conducted the present study to assess the surgical profile among patients of ileal perforation.

\section{MATERIALS \& METHODS}

The present prospective study was conducted at department of general surgery of our tertiary care 
hospital. The study duration was of two years from June 2016 to July 2018. A sample size of 50 was calculated at $95 \%$ confidence interval at $5 \%$ acceptable margin of error by epi info software version 7.2. Patients who were diagnosed as perforation and peritonitis on the basis of laboratory diagnosis and clinical examination were enrolled by simple random sampling. Clearance from Institutional Ethics Committee was taken before start of study. Written informed consent was taken from each study participant.

The data were collected by predesigned Performa after randomization of the patients among two groups according to surgical procedure group $A$ (primary repair) and group B (loop ileostomy). Patients who had chronic debleating diseases, patients who were on steroid therapy or suffering from malignancy were excluded from the present study. The antibiotics (ceftriaxone, ceftazidime and metronidazole) were given in both groups before surgery. Data analysis was carried out using SPSS v22. All tests were done at alpha (level significance) of $5 \%$; means a significant association present if $p$ value was less than 0.05 .

\section{RESULTS}

In the present study the we enrolled 50 Patients of ileal perforation among each group after randomization of study participants. So that we can get equal comparable study participants. Total study participants were classified in two major groups according to the surgical procedure used. Among the primary repair group, $16(32 \%)$ patients were in the age group of $21-40$ years, $30(60 \%)$ cases were in the age group of $41-60$ years and $4(8 \%)$ patients were in the age group of $61-80$ years. Among the ileostomy closure group, 15 (30\%) patients were in the age group of 21-40 years, $32(64 \%)$ cases were in the age group of $41-60$ years and $3(6 \%)$ patients were in the age group of 61-80 years. However, this distribution was statistically non-significant $(P$ value $>0.05)$. Among the primary repair group, 38 (76\%) patients were male and 12 (24\%) patients were female. Among the ileostomy closure group, 36(72\%) patients were male and 14 (28\%) patients were female. However, this distribution was statistically nonsignificant ( $P$ value $>0.05$ ).

(Table 1)
Table 1: Age and gender wise distribution in both the groups.

\begin{tabular}{|l|l|l|l|l|}
\hline \multicolumn{2}{|l|}{ Parameters } & $\begin{array}{l}\text { primary } \\
\text { repair }\end{array}$ & $\begin{array}{l}\text { loop } \\
\text { ileostomy }\end{array}$ & \multirow{2}{*}{ p value } \\
\hline \multirow{2}{*}{$\begin{array}{l}\text { Age } \\
\text { (Years) }\end{array}$} & $21-40$ & $16(32 \%)$ & $15(30 \%)$ & \multirow{2}{*}{$>0.05$} \\
\cline { 2 - 4 } & $41-60$ & $30(60 \%)$ & $32(64 \%)$ & \\
\cline { 2 - 4 } & $61-80$ & $4(8 \%)$ & $3(6 \%)$ & \\
\hline \multirow{2}{*}{ Gender } & Male & $38(76 \%)$ & $36(72 \%)$ & \multirow{2}{*}{$>0.05$} \\
\cline { 2 - 4 } & Female & $12(24 \%)$ & $14(28 \%)$ & \\
\hline
\end{tabular}

In the present study, out of total study participants abdominal pain was the most common presenting symptom present in patients which was followed by fever, abdominal distension and vomiting. On the basis of time of perforation, $4 \%$ cases presented within 12 hour, between 12 and 24 hour was reported among in 50\% cases, in the rage of 24 and 48 hour seen in $24 \%$ patients, in the range of 48 and 72 hour reported in $12 \%$ cases, in range of 72 and 96 hour reported in $8 \%$ cases, and in range of 96 and 120 hour reported in $2 \%$ case. Near about all patients were operated in the range of 12 hours of hospitalization. We found that majority of cases had circular perforation of typhoid at antimesenteric border which was followed by tubercular elliptical perforation on the antimesenteric border and traumatic type perforation. (Table 2)

Table 2: Distribution according to clinical presentation.

\begin{tabular}{|l|l|}
\hline Presenting symptom & Number of patients \\
\hline Abdominal pain & $61 \%$ \\
\hline Fever & $52 \%$ \\
\hline Abdominal distension & $46 \%$ \\
\hline Vomiting & $42 \%$ \\
\hline Obstipation & $40 \%$ \\
\hline Trauma & $4 \%$ \\
\hline
\end{tabular}

\section{DISCUSSION}

In the present study the we enrolled 50 Patients of ileal perforation among each group after randomization of study participants. So that we can get equal comparable study participants. Total study participants were classified in two major groups according to the surgical procedure used. Among the primary repair group, $16(32 \%)$ patients were in the age group of $21-40$ years, $30(60 \%)$ cases were in the age group of $41-60$ years and $4(8 \%)$ patients were in the age group of $61-80$ years. Among the ileostomy closure group, $15(30 \%)$ patients were in the age group of $21-40$ years, 32 (64\%) cases were in the age 
group of $41-60$ years and $3(6 \%)$ patients were in the age group of $61-80$ years. However, this distribution was statistically non-significant $(P$ value $>0.05)$. Among the primary repair group, 38 (76\%) patients were male and $12(24 \%)$ patients were female. Among the ileostomy closure group, 36(72\%) patients were male and $14(28 \%)$ patients were female. However, this distribution was statistically nonsignificant $(P$ value $>0.05)$. Similar results were obtained in a study conducted by Wani et al among patients with perforation of gastrointestinal tract they reported that higher prevalence of males were affected than females in the ratio of 3: 1 (7). Similar results were obtained in a study conducted by Adesunkanmi et al among patients with perforation of gastrointestinal tract they reported that higher prevalence of males were affected than females in the ratio of $4: 1$ (8).

In the present study, out of total study participants abdominal pain was the most common presenting symptom present in patients which was followed by fever, abdominal distension and vomiting. Similar results were obtained in a study conducted by Talwar et al among patients with perforation of gastrointestinal tract they reported that abdominal pain was the most common presenting symptom present in patients which was followed by fever, abdominal distension, vomiting and obstipation (9). Similar results were obtained in a study conducted by Beniwal et al among patients with perforation of gastrointestinal tract they reported that the most common presenting symptoms present among patients were abdominal pain, abdominal distension, vomiting, fever and obstipation (10). Similar results were obtained in a study conducted by Prasad et al among patients with perforation of gastrointestinal tract they reported that the most common presenting symptoms present among patients were abdominal pain, abdominal distension, vomiting and obstipation (11).

In the present study, on the basis of time of perforation, 4\% cases presented within 12 hour, between 12 and 24 hour was reported among in 50\% cases, in the rage of 24 and 48 hour seen in $24 \%$ patients, in the range of 48 and 72 hour reported in $12 \%$ cases, in range of 72 and 96 hour reported in $8 \%$ cases, and in range of 96 and 120 hour reported in $2 \%$ case. Near about all patients were operated in the range of 12 hours of hospitalization. Similar results were obtained in a study conducted by Nadkarni et al among patients with perforation of gastrointestinal tract they reported that majority of patients were presented within 90 hours based ontime of perforation (12).

In the present study, we found that majority of cases had circular perforation of typhoid at antimesenteric border which was followed by tubercular elliptical perforation on the antimesenteric border and traumatic type perforation. Similar results were obtained in a study conducted by Nadkarni et al among patients with perforation of gastrointestinal tract they reported that most common etiology was nonspecific cause of ileal perforation which was followed by typhoid and tubercular perforation (12). Similar results were obtained in a study conducted by Visser A et al among patients with perforation of gastrointestinal tract they reported that most common etiology was typhoid and tubercular perforation (13).

\section{CONCLUSION}

We concluded from the present study that the most common presenting symptoms present among patients were abdominal pain, abdominal distension, vomiting, fever and obstipation. We found that majority of cases had circular perforation of typhoid at antimesenteric border which was followed by tubercular elliptical perforation on the antimesenteric border and traumatic type perforation.

\section{REFERENCES}

1. Kim SH, Shin SS, Jeong YY, Heo SH, Kim JW, Kang HK. Gastrointestinal tract perforation: MDCT findings according to the perforation sites. Korean J Radiol [Internet]. 2009 [cited 2018 Jan 22];10(1):63-70. Available from:http://www.ncbi.nlm.nih.gov/pubmed /19182505

2. Munghate A, Kumar A, Mittal S, Singh H, Sharma J, Yadav M. Acute Physiological and Chronic Health Evaluation II Score and its Correlation with Three Surgical Strategies for Management of Ileal Perforations. J Surg Tech Case Rep [Internet]. 2015 [cited 2018 Jan 22];7(2):32-6. Available from: http://www.ncbi.nlm.nih.gov/ pubmed/27512550

3. Sharma A, Sharma R, Sharma S, Sharma A, Soni D. Typhoid intestinal perforation: 24 perforations in one patient. Ann Med Health Sci Res [Internet]. 2013 Nov [cited 2018 Jan 22];3(Suppl 1):S41-3. Available from: http://www.ncbi.nlm.nih.gov/pubmed/24349848

4. Faulkner CT, Garcia BB, Logan MH, New JC, Patton S. Prevalence of endoparasitic infection in children and its relation with cholera prevention efforts in Mexico. Rev Panam Salud Publica [Internet]. 2003 Jul [cited 
Dr. B.M.Soni, International Journal of Medical and Biomedical Studies(IJMBS)

2018 Jan 22];14(1):31-41. Available from: http://www.ncbi.nlm.nih.gov /pubmed/12952605

5. Lopez N, Kobayashi L, Coimbra R. A Comprehensive review of abdominal infections. World J Emerg Surg [Internet]. 2011 Feb 23 [cited 2018 Jan 22];6:7. Available from: http://www.ncbi.nlm.nih.gov/pubmed/21345232

6. Mittal S, Singh $H$, Munghate A, Singh G, Garg A, Sharma J. A Comparative Study between the Outcome of Primary Repair versus Loop lleostomy in Ileal Perforation. Surg Res Pract [Internet]. 2014 Mar 27 [cited 2018 Jan 22];2014. Available from: https://www.hindawi.com/journals/srp/2014/729018 I

7. Wani RA, Parray FQ, Bhat NA, Wani MA, Bhat TH, Farzana $F$. Nontraumatic terminal ileal perforation. World J Emerg Surg [Internet]. 2006 Mar 24 [cited 2018 Jan 22];1:7. Available from: http://www.ncbi.nlm.nih.gov/pubmed/16759405

8. Adesunkanmi ARK, Badmus TA, Fadiora FO, Agbakwuru EA. Generalized peritonitis secondary to typhoid ileal perforation: Assessment of severity using modified APACHE II score. 2005 Dec 31 [cited 2018 Jan 22]; Available from: https://tspace.library.utoronto.ca/handle/1807/6271

9. Talwar S, Sharma RK, Mittal DK, Prasad P. TYPHOID ENTERIC PERFORATION. ANZ J Surg [Internet]. 1997
Jun 1 [cited 2018 Jan 22];67(6):351-3. Available from: http://doi.wiley.com/10.1111/j.1445-2197. 1997.tb01990.x

10. Beniwal US, Jindal D, Sharma J, Jain S, Shyam G. Comparative study of operative procedures in typhoid perforation. 2003 Dec 31 [cited 2018 Jan 22]; Available from: https://tspace.library. utoronto.ca /handle/1807/20413

11. Prasad PB, Choudhury DK, Prakash O. Typhoid perforation treated by closure and proximal side to side ileotransverse colostomy. J Indian Med Assoc [Internet]. 1975 Dec 1 [cited 2018 Jan 22];65(11):297-9. Available from: http://www.ncbi.nlm.nih.gov/pubmed/1223220

12. Nadkarni KM, Shetty SD, Kagzi RS, Pinto AC, Bhalerao RA. Small-bowel perforations. A study of 32 cases. Arch Surg [Internet]. 1981 Jan [cited 2018 Jan 22];116(1):53-7. Available from: http://www.ncbi.nlm.nih.gov/pubmed/7469733

13. van Westreenen HL, Visser A, Tanis PJ, Bemelman WA. Morbidity related to defunctioning ileostomy closure after ileal pouch-anal anastomosis and low colonic anastomosis. Int J Colorectal Dis [Internet]. 2012 Jan [cited2018Jan22];27(1):49-54.Availablefrom :http://www.ncbi.nlm.nih.gov/pubmed/21761119 